\title{
Memoria histórica del movimiento campesino de Chalatenango, de Carlos Benjamín Lara Martínez
}

Adriana Alas

El Colegio de Michoacán

Fue a principios de 2008 que leí por primera vez algunos fragmentos de lo que ahora publica UCA Editores como Memoria histórica del movimiento campesino de Chalatenango. Nuestro autor, Carlos Lara Martínez, utilizaba estos fragmentos para que, como estudiantes de antropología, leyéramos sobre qué es la memoria social, la memoria histórica y cómo se había elaborado este proyecto de investigación. A través de sus páginas pudimos comenzar a pensar nuestras propias preguntas y las estructuras iniciales de nuestras investigaciones. El impulso de Carlos Lara Martínez para entender las repoblaciones en el país contagió a muchos de los que entonces estudiábamos la Licenciatura en Antropología Sociocultural en la Universidad de El Salvador. Por tanto, podría argumentar que este libro ha inspirado otras investigaciones sobre las repoblaciones en Morazán, Cuscatlán y Chalatenango (Guardado Torres, 2013; Durán Fernández, 2013; Alas López, 2013). El libro de Carlos Lara Martínez, así como las investigaciones citadas, se inserta dentro de cierta producción académica para el estudio de El Salvador; el diálogo con estas producciones es lo que profundizo a continuación.

\section{El problema de los acentos en la investigación}

Han sido muchas las investigaciones sobre memoria social que se han realizado en la posguerra salvadoreña. Estas han variado en sus enfoques teóricos y propuestas metodológicas; además, han respondido a diversos intereses por parte de los investigadores, quienes en muchos casos han estado vinculados, de una u otra forma, a la experiencia 
del conflicto armado, principalmente como simpatizantes de la insurgencia. Sin embargo, una característica común en estos estudios es que, a pesar de la Ley de Amnistía (1993) y el discurso hegemónico de "perdón y olvido" que se impulsó junto a esta ley, el paso de los años ha demostrado la emergencia de más relatos sobre las experiencias de la guerra de los 80 . En otras palabras, la figura del olvido no ha sido privilegiada entre los exinsurgentes, al contrario, qué y cómo recuerdan la guerra es fundamental.

En este sentido, un debate que cruza las investigaciones sobre memoria social histórica, antropológica y sociológica han sido las comunidades repobladas de la guerra como Guarjila y San Antonio Los Ranchos. En las repoblaciones, la memoria, la violencia, la continuidad de prácticas políticas autoritativas, así como la implementación de otras formas de gobernar más o menos democráticas han sido el fértil campo de trabajo de algunos investigadores en una relación de continuidad con el conflicto político militar y sus memorias. La investigación de Carlos Lara Martínez se ubica en esta discusión sobre las repoblaciones, dicha discusión podría ser uno de los debates contemporáneos más fructíferos para la antropología y las ciencias sociales en El Salvador.

En las repoblaciones nos planteamos: ¿quiénes repueblan?, ¿de dónde vienen? y ¿dónde están los pobladores anteriores? Estas son preguntas que han sido abordadas desde múltiples miradas; sin embargo, uno de los debates que considero central, y que la investigación de Carlos Lara Martínez aporta, es si podemos entender a las repoblaciones, en términos de Carlos Lara, como: "un nuevo tipo de sociedad y cultura" con base en la experiencia revolucionaria que contribuye a una mejor vida organizativa y social o como poblaciones en las que los traumas de la guerra, la envidia, las relaciones clientelares y la violencia siguen latentes. Estos dos polos pueden ser esbozados a grandes rasgos en tres subgrupos. Primero, autores como Jenny Pearce (1986), Beatrice Edwards y Gretta Tovar (1991), Molly Todd (2010) y Carlos Lara Martínez (2018) entienden a la población que habita en las repoblaciones bajo el paradigma de la agencia de las familias campesinas y la propia construcción de sus localidades a partir de la experiencia insurgente. Segundo, autores como Ralph Sprenkels (2018), Phillipe Bourgois (2001), Leigh Binford (1996), Irina Silber (2011) y Elizabeth Wood (2003) se han enfocado en estudiar el fenómeno de las repoblaciones poniendo al centro las relaciones de poder, con respecto a las organizaciones político-militares, las políticas neoliberales y el clientelismo local. Tercero, un grupo más escaso, entre quienes podemos mencionar de nuevo a Bourgois (2001), Silber (2011) y también a Julia Dickson-Gómez (2002), ha enfatizado el trauma social 
en las repoblaciones con base en la repetición de la violencia insurgente y contrainsurgente en las relaciones sociales que se establecen al interior de las repoblaciones.

¿En qué radica la diferencia de tantas lecturas sobre poblaciones similares o, incluso, a veces sobre la misma población?, ¿cómo pueden estas etnografías apuntar en múltiples direcciones? En principio, creo que es posible citar las reflexiones sobre autoetnografía de Mary Louise Pratt, quien argumenta: "si los textos etnográficos son aquellos en los que los sujetos metropolitanos europeos se representan a sí mismos en los otros (usualmente los otros conquistados), los textos autoetnográficos son representaciones que los otros definidos construyen en respuesta o en diálogo con esos textos" (Pratt, 1991, p. 35). En este sentido, Carlos Lara Martínez, como un investigador local, dialoga con lo que investigadores extranjeros (como los que he citado) interpretan sobre las repoblaciones. Por tanto, los múltiples resultados de las etnografías citadas no siempre implican automáticamente o en todos los sentidos la negación de la otra, sino diferentes acentos que estos textos presentan o profundizan. Con esto no quiero decir que no sean textos criticables, ni que debamos caer en el relativismo total, quiero decir que una crítica debe tomarse en cuenta desde el lugar en que se produce el conocimiento y, entonces, la experiencia del autor mismo.

En definitiva, el debate de las repoblaciones sigue siendo un debate abierto, puesto que estamos, como lo vemos con el libro de Carlos Lara Martínez, en el momento de la formación de sujetos antropológicos a partir del análisis de los nuevos valores creados desde la experiencia revolucionaria que el conflicto político militar y sus conexiones más amplias les deja.

\section{Sobre el desarrollo del argumento y los datos etnográficos}

En su libro Los hundidos $y$ los salvados (1986), Primo Levi reflexiona sobre los sujetos que emergen después de la violencia del holocausto judío. Siguiendo sus reflexiones, la violencia de la guerra en El Salvador, aunque devastadora, no fue solamente esto, también permitió, en palabras de Veena Das, la emergencia de "otras formas de habitar el mundo" (Veena Das, 2008). El libro de Carlos Lara Martínez acentúa, precisamente, esas otras formas de habitar el mundo que él denomina como un "nuevo tipo de sociedad y cultura" a partir de la solidaridad, la equidad y la participación de los integrantes de la comunidad en la toma de decisiones. Por medio de un análisis detallado de una serie datos etnográficos compuestos por 
entrevistas a profundidad, pláticas informales, rituales o celebraciones y, en general, la convivencia prolongada con los semicampesinos revolucionarios del oriente de Chalatenango, Lara Martínez indaga en los valores profundos de estas poblaciones a partir de un enfoque semiótico combinado con la etnohistoria.
El autor, por supuesto, no parte de un punto cero en sus interpretaciones y, por eso, la primera parte del libro se encarga de documentar, a través de los relatos situados, la vida antes del conflicto político militar y, en su interpretación, también toma en cuenta el pasado prehispánico y la conversión al cristianismo. En ese sentido, nuestro autor nos dice:

\begin{abstract}
El discurso de la memoria histórica de estos pequeños agricultores constituye un medio para construir una cultura nueva en Guarjila y San Antonio Los Ranchos, la cual se crea a través de un proceso que reproduce concepciones y valores sociales preexistentes, pero que también produce nuevos valores y concepciones que construyen sistemas culturales nuevos (Lara Martínez, 2018, p. 27).
\end{abstract}

El autor examina por medio de lo que denomina "diálogos" estos valores y concepciones. La sección de los diálogos, segunda parte del libro, considero que es una de las etapas más creativas de la investigación, puesto que con la palabra "diálogo" también invita al lector a la movilidad, a la escucha y, posteriormente, a la interpretación. El libro de Carlos Lara Martínez es sumamente rico en datos cualitativos, datos producidos en contextos etnográficos que entregan al lector un archivo impresionante; de este modo, será nuestro trabajo, como lectores e investigadores, hacerle nuevas preguntas e interpretaciones en contraste con el aquí y el ahora.

\section{Estos datos etnográficos} conducen a Carlos Lara Martínez a lo que considero que son algunos de los aportes principales de su investigación, de los cuales mencionaré cinco de ellos. Primero, la definición de "memoria histórica", este término ha sido constantemente un desliz en el discurso académico o político: ¿qué exactamente es "memoria histórica"? Carlos Lara Martínez nos provee, estemos o no completamente de acuerdo, un concepto que nos permite pensar la memoria histórica y sus consecuencias. El autor entiende la memoria histórica como "un discurso que establece periodos de tiempo más o menos definidos, con base a un esfuerzo que los sujetos sociales realizan por precisar las fechas en las que sucedieron los acontecimientos que narran. Conceptos como clase social, sistema capitalista dominante, oligarquía, etc., son elementos que provienen de las ciencias sociales y que se han 
integrado a este discurso de la memoria histórica de los pequeños agricultores de Guarjila y Los Ranchos" (Lara Martínez, 2018, p. 17). Este concepto ha sido producto del método etnográfico utilizado por el autor para el estudio del discurso y la memoria, en sus palabras: "como un proceso social que está integrado a la dinámica de la sociedad y la cultura como un todo" (Lara Martínez, 2018, p. 18), es decir, el sello holístico de la metodología de investigación del autor.

Segundo, rastrea y constata cómo el elemento clave, en el discurso histórico de estas comunidades, es la oposición al sistema de la sociedad capitalista dominante y cómo eso se mantiene a través de la figura del FMLN como partido político (al menos hasta el momento en que se realizó la investigación).

Tercero, un elemento particularmente valioso es el entendimiento del oriente de Chalatenango como una microrregión y, por tanto, una identidad microrregional ligada a la experiencia revolucionaria, la cual está atravesada por relaciones de poder que marginan u opacan otras experiencias, como la de los campesinos afines a la política de derecha que viven en las repoblaciones. Considero que la idea de microrregión podría, en investigaciones futuras, colaborar con el anonimato y seguridad de la población que accede a participar en las investigaciones realizadas en el oriente de Chalatenango.
Cuarto, el análisis semiótico, en particular, del sentido de "libertad" para estas poblaciones. La libertad no ligada a la individualidad necesariamente, sino prioritariamente ligada a la libertad de una vida comunitaria y a la autodeterminación, en la medida de los recursos a los que ellos puedan acceder 0 negociar con quienes los poseen. En este sentido, es una libertad democrática al decidir la mejor forma de organizar su localidad.

Quinto, el carácter agonístico del discurso histórico. Una de las pistas más importantes sobre estas poblaciones que Carlos Lara Martínez nos brinda es que las causas del conflicto aún se mantienen dado el cierre negociado del conflicto armado $y$, por tanto, el discurso histórico continuará dando en sentido de lucha en la sociedad local. Para profundizar en este punto, recomiendo en especial el capítulo VII sobre la dimensión ritual. En general, la amplitud de los datos y de las interpretaciones de Carlos Lara Martínez, bien podrían abonar a otros estudios sobre la base militante del FMLN, por ejemplo, el estudio sobre las comunidades de memoria de Erick Ching (2016).

En definitiva, estemos o no de acuerdo con las palabras del autor y sus conclusiones, el libro de Carlos Lara Martínez es un meticuloso aporte a la antropología en El Salvador y, en general,a las sociedades de posguerra de América Latina; de este modo, será nuestra tarea la lectura crítica de esta importante investigación. 


\section{Referencias bibliográficas}

Alas López, A. A. (2013). La dinámica de los grupos domésticos en una repoblación al oriente de Chalatenango, Municipio de Las Vueltas, Cantón La Ceiba (20112013). Tesis de Licenciatura en Antropología Sociocultural. Universidad de El Salvador.

Binford, L. (1996). The Mozote Masssacre: Anthropology and Human Rights. Tucson: University of Arizona Press.

Bourgois, P. (2001). The power of violence in war and peace: Post-Cold War lessons from El Salvador. Ethnography 2 (1), pp. 5-34.

Ching, E. (2016). Stories of Civil War in El Salvador: A Battle Over Memory. North Carolina: University of North Carolina Press.

Das, V. (2008). “Violencia, conocimiento envenenado y subjetividad”, en Francisco Ortega (Ed.), Sujetos de dolor, agentes de dignidad. Bogotá: Pontificia Universidad Javeriana y Universidad Nacional de Colombia.

Dickson-Gómez, J. (2002). The Sound of Barking Dogs: Violence and Terror among Salvadorean Families in the Post-War. Medical Anthropology 16 (4), pp. 415-438.

Durán Fernández, J. V. (2013). Fundación de la Comunidad La Mora: ritual y dinámica de las identidades políticas y sociales (Suchitoto 2013-2013). Tesis de Licenciatura en Antropología Sociocultural. Universidad de El Salvador.

Edwards, B. y Tovar Siebentritt G. (1991). Places of Origin. The Repopulation of Rural El Salvador. Boulder: Lynne Rienner Publishers.

Guardado Torres, C. M. (2013). Transformación sociocultural en los Quebrachos Jocoaitique, una visión desde la posguerra (Morazán, 2011-2013). Tesis de Licenciatura en Antropología Sociocultural. Universidad de El Salvador.

Lara Martínez, C. B. (2018). Memoria histórica del movimiento campesino de Chalatenango. La Libertad: UCA Editores.

Levi, P. (1986). Los hundidos y los salvados. Madrid, España: Península.

Pearce, J. (1986). Promised Land: peasant rebellion in Chalatenango, El Salvador. Londres: Latin America Bureau.

Pratt, M. L. (1991). Arts of the Contact Zone. Modern Language Association (pp. 33-40). 
Silber, I. (2011). Everyday Revolutionaries. New Brunswick, N.J: Rutgers University Press.

Sprenkels, R. (2018). After insurgency. Revolution and Electoral Politics in El Salvador. Indiana: University of Notre Dame Press.

Todd, M. (2010). Beyond Displacemente. Campesinos, Refugees and Collective Action in the Salvadorean Civil War. Madison: The University of Wisconsin.

Wood, E. (2003). Insurgent Collective Action and Civil War in El Salvador. Cambridge: Cambridge University Press. 